\title{
Low-UWB Receiving Antenna for WCE Localization
}

\author{
Chaïmaâ Kissi \\ Electronics and Telecommunication \\ Systems Research Group, National \\ School of Applied Sciences (ENSA) \\ Ibn Tofail University \\ Kenitra, Morocco \\ chaimaakissi1@gmail.com
}

Marko Sonkki

Centre for Wireless Communications,

Faculty of Information Technology and

Electrical Engineering

University of Oulu

Oulu, Finland

marko.sonkki@oulu.fi

\author{
Mariella Särestöniemi \\ Centre for Wireless Communications, \\ Faculty of Information Technology and \\ Electrical Engineering \\ University of Oulu \\ Oulu, Finland \\ mariella.sarestoniemi@oulu.fi
}

Sami Myllymäki

Microelectronics Research Unit,

Faculty of Information Technology and Electrical Engineering

University of Oulu

Oulu, Finland

sami.myllymaki@oulu.fi

\author{
Carlos Pomalaza Raez \\ Department of Electrical and Computer \\ Engineering \\ Purdue University \\ Fort Wayne, Indiana 46805, USA \\ cpomalaz@purdue.edu
}

\author{
Timo Kumpuniemi \\ Centre for Wireless Communications, \\ Faculty of Information Technology and \\ Electrical Engineering \\ University of Oulu \\ Oulu, Finland \\ timo.kumpuniemi@oulu.fi
}

Mohamed Nabil Srifi

Electronics and Telecommunication

Systems Research Group, National

School of Applied Sciences (ENSA)

Ibn Tofail University

Kenitra, Morocco

srifimn@gmail.com

\begin{abstract}
The paper introduces a novel antenna operating in the UWB band 3.75-4.25 GHz for BAN (Body Area Networks) applications. The proposed antenna has omnidirectional and directional radiation patterns in absence and presence of a backed air-filled cavity, respectively. The antenna was simulated using CST Microwave Studio software, showing maximum realized gains of 2.6 and $7.37 \mathrm{~dB}$ with and without the cavity, respectively. The designed antenna is planned to have the role of a receiving antenna for wireless capsule localization purposes. Therefore, an initial on-body study was required and detailed in this paper giving the focus on the small-intestine area, since it is the vital human body part of interest for capsule tracking and monitoring. An onbody scenario is presented using two antenna structures and compared with the free-space results. SAR (Specific Absorption Rate) is also investigated in compliance with IEEE/IEC 42704-1 standard. These initial studies prove that the antenna can be regarded a good candidate for WCE (Wireless Capsule Endoscopy) localization.
\end{abstract}

Keywords-BAN, Body Area Networks, High antenna gain, IEEE 802.15.6 standard, small-intestine, Ultra-wide band, Wireless Capsule Endoscopy

\section{INTRODUCTION}

During the last decades, wearable antennas and sensor development have arisen to answer the medical application needs [1]. In this context, BAN (Body Area Networks) comes to meet the required guidelines which are detailed in IEEE 802.15.6 standard [2-3]. One of the applications appealing such efficient wearable antennas is the WCE (Wireless Capsule Endoscopy) localization by promoting UWB bands suitable for reliable wireless communication link and for high image resolution with low path losses [4$6]$. The relevant body part of interest for this application is the GI (Gastro Intestinal) tract, especially the small-intestine area [7-8]. In this regard, several studies have been conducted by pointing out the promotion of the selected UWB band (3.75-4.25 GHz). Furthermore, an accurate localization calls out for efficient tracking algorithms and high directive receiving antennas. Therefore, the main challenging task relays on the design of a high directive receiving antenna for out-body to in-body communications [9].

A novel antenna structure is defined in this paper. The antenna is firstly introduced by a single antenna, to which a cavity was added later. Both structures are operating at lowUWB band in compliance with IEEE 802.15.6 standard for BAN. The antenna configuration is analyzed in first section, followed by the cavity-backed approach investigations. The third section discusses the antenna performances in vicinity to human body. Last section provides future working plans.

\section{ANTENNA STRUCTURE AND CONFIGURATION ANALYSIS}

\section{A. Single antenna}

The antenna is printed on $0.8 \mathrm{~mm}$-FR4 substrate material $\left(\varepsilon_{\gamma}=4.3\right)$. The antenna radiating part is made of the concatenation of two symmetrical circles, fed at their intersection by a microstrip line of $1.5 \mathrm{~mm}$ width and $14.0 \mathrm{~mm}$ length. The ground plane is an association/composition of a circle and rectangle-shaped structures as illustrated in Fig. 1. The antenna overall size is $47.5 \times 47.5 \times 0.8 \mathrm{~mm}^{2}$. The optimized parameters of the proposed single antenna are summarized in Table I.

Figure 2 shows the return loss of the proposed single Low-UWB antenna by tuning the feeding line width (Wf). It is clearly seen that this parameter is mainly responsible of 
an undesired resonance frequency at $0.25 \mathrm{GHz}$. Increasing this value from 1.5 to $3 \mathrm{~mm}$ do not affect the upper frequency band, whereas it shifts slightly the lower frequency from 3.50 to $3.53 \mathrm{GHz}$. The optimized value is $3 \mathrm{~mm}$, and this choice was confirmed by the input impedance study illustrated in Fig. 3, which shows a good match of about $49.3-\mathrm{j} 1.97 \Omega$ suitable with a practical use where the antenna is fed by a $50 \Omega$ coaxial cable.

A concise parametric study is done restrained to R1, R2 and Rg tuning. Parameters R1 and R2 affect significantly the antenna matching. It is clearly seen from Fig. 4 and 5 that both tuning parameters has similar impact on the results. In other words, as the radius increases from 8 to $10 \mathrm{~mm}$ the antenna bandwidth shifts to the left. The required bandwidth of (3.75-4.25 GHz) is covered entirely with value of $9 \mathrm{~mm}$. Nonetheless, while maintaining R1 set to $9 \mathrm{~mm}$ and varying slightly R2 the undesired frequency start to disappear. This confirms the feeding sensitivity to R2 in addition to Wf parameter. Fig. 6 shows that the $-10 \mathrm{~dB}$ bandwidth antenna matching is very sensitive to the $\mathrm{Rg}$ parameter. The optimized value is chosen to $9 \mathrm{~mm}$.

The antenna has a bandwidth of (3.47-4.27 GHz), which is suitable to cover the required bandwidth defined by IEEE 802.15.6 (BAN) of (3.75-4.25 GHz). The resonant frequency is $3.88 \mathrm{GHz}$ with a return loss of $-32.4 \mathrm{~dB}$. Whereas, the reported reflection coefficient at $4 \mathrm{GHz}$ is $-19.5 \mathrm{~dB}$. The antenna radiates well over the frequency band of our interest, according to Fig. 7 showing a simulated total efficiency value between -1.2 and $0.7 \mathrm{~dB}$. Besides, the surface current distribution over the radiating element reveals that the highest intensity is concentrated in the circles intersection from Fig. 8.

The antenna has an omni-directional radiation pattern as depicted in Fig. 9. The single antenna achieves an acceptable maximum directivity and realized gain of $3.3 \mathrm{dBi}$ and $2.6 \mathrm{~dB}$ at $4 \mathrm{GHz}$, respectively, as reported in Table II.

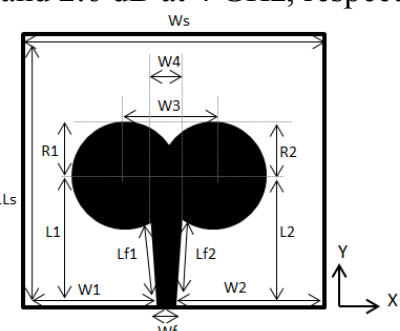

(b)
Fig. 1. Geometry of the proposed UWB antenna. (a) Front side (b) Back side.

TABLE I: OPTIMIZED PARAMETERS OF THE PROPOSED UWB ANTENNA

\begin{tabular}{|l|l|l|l|}
\hline Parameter & Value $(\mathrm{mm})$ & Parameter & Value $(\mathrm{mm})$ \\
\hline Ws & 47.5 & L1 & 21.5 \\
\hline Ls & 47.5 & L2 & 21.5 \\
\hline hs & 0.8 & Lg1 & 14.9 \\
\hline W1 & 22.75 & Lg2 & 8.4 \\
\hline W2 & 23.25 & Rg & 9 \\
\hline Wf & 1.5 & R1 & 9 \\
\hline W3 & 8 & R2 & 9 \\
\hline W4 & 3 & Wg1 & 23.75 \\
\hline Lf1 & 14.02 & Wg2 & 23.75 \\
\hline Lf2 & 14.02 & & \\
\hline
\end{tabular}

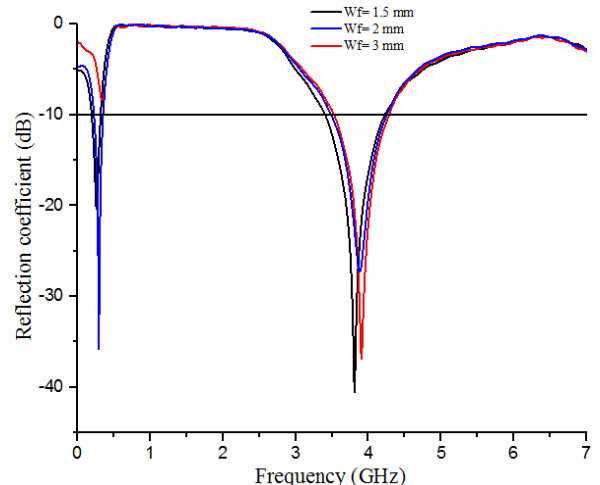

Fig. 2. Reflection coefficient of the proposed UWB antenna by tuning Wf.

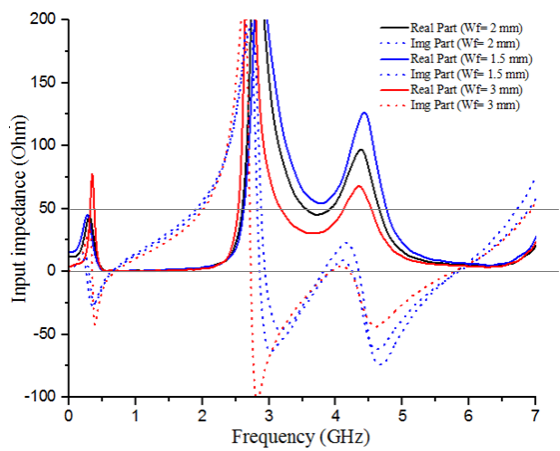

Fig. 3. Reflection coefficient of the proposed Low-UWB single antenna by tuning Wf.

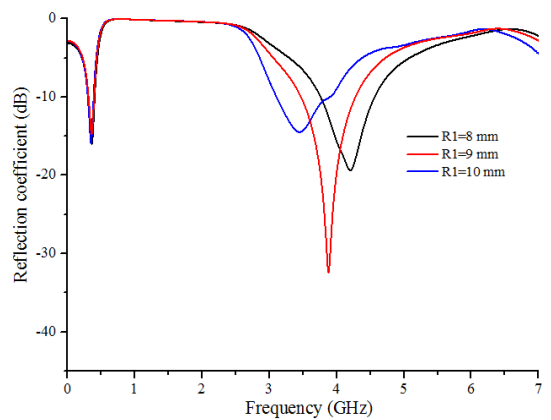

Fig.4. Reflection coefficient of the proposed Low-UWB single antenna by tuning R1.

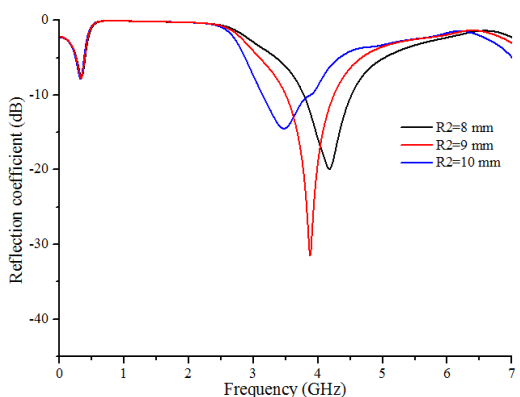

Fig. 5. Reflection coefficient of the proposed Low-UWB single antenna by tuning R2.

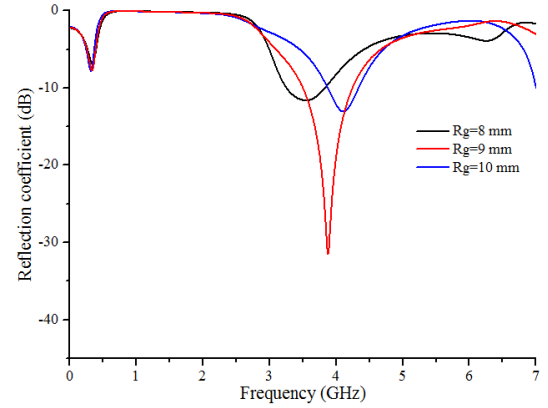

Fig. 6. Reflection coefficient of the proposed Low-UWB single antenna by tuning $\mathrm{Rg}$. 


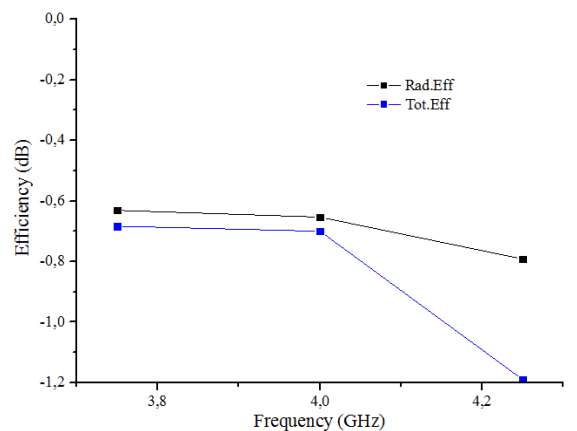

Fig. 7. Radiation and Total efficiencies of the proposed Low-UWB single antenna.

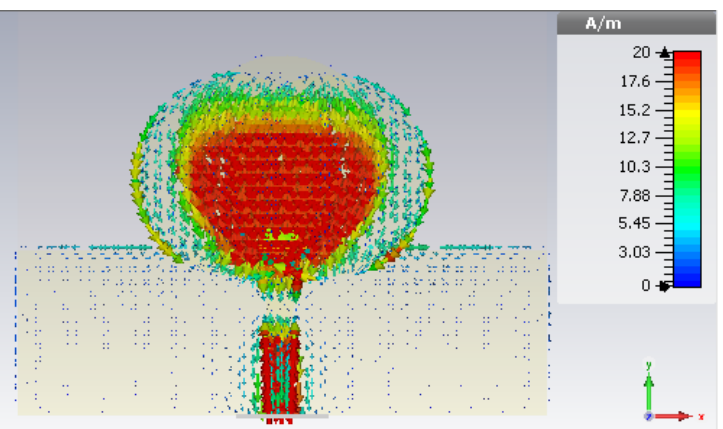

Fig. 8. Surface current distribution of the single Low-UWB antenna at $4 \mathrm{GHz}$.
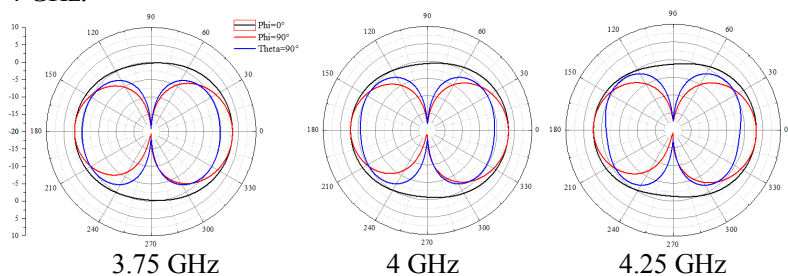

Fig. 9. Radiation pattern in $\mathrm{dBi}$ of the single Low-UWB antenna.

TABLE II: REALIZED GAIN VALUES OF THE LOW-UWB SINGLE ANTENNA

\begin{tabular}{|c|c|c|c|}
\hline $\begin{array}{c}\text { Frequency } \\
(\mathrm{GHz})\end{array}$ & $\begin{array}{c}\mathrm{Phi}=0^{\circ} \\
(\mathrm{dB})\end{array}$ & $\begin{array}{c}\text { Phi }=90^{\circ} \\
(\mathrm{dB})\end{array}$ & $\begin{array}{c}\text { Theta }^{\circ} 90^{\circ} \\
(\mathrm{dB})\end{array}$ \\
\hline 3.75 & 2.60 & 2.61 & -0.65 \\
\hline 4 & 2.58 & 2.60 & -0.76 \\
\hline 4.25 & 2.03 & 2.05 & -0.80 \\
\hline
\end{tabular}

\section{B. Cavity-backed approach}

In this subsection, the previously presented antenna is completed by the introduction of the cavity as illustrated in Fig. 10. Its importance lies in the fact that the cavity backed approach ensure better directivity and also a higher gain, which are both key requirements/factors for receiving antenna. The cavity box is made of Copper material of $0.5 \mathrm{~mm}$-thickness with overall dimensions of $85.5 \times 8.6 \times 30.87 \mathrm{~mm}^{2}$. After a careful/attentive study by tuning the cavity paramereters, the adequate chosen antenna position is inside the cavity center with the following parameter values: $\mathrm{X}=\mathrm{Y}=\mathrm{Z} 1=20 \mathrm{~mm}$ and $\mathrm{Z} 2=10 \mathrm{~mm}$.

The cavity dimension and the antenna position are relevant for the antenna configuration as shown in Fig. 11 (a). A five parameter combinaison is presented, it is clearly noted that the antenna bandwidth is sensitive to these aformentioned parameters. After a careful and fine tuning analysis, it is concluded that the final cavity-backed antenna dimensions are $X=Z 1=18.75 \mathrm{~mm}$, which equals to $\lambda / 4$ at the $4 \mathrm{GHz}$ center frequency, $\mathrm{Y}=2 \mathrm{~mm}$ and $\mathrm{Z} 2=0 \mathrm{~mm}$. This comes with the idea to optimize the cavity box to a smallsize structure and meet the requirements of the Low-UWB band defined by IEEE 802.15.6 standard for BAN (Body Area Networks) applications.

The cavity-backed antenna has a -10 bandwidth of (3.50$4.36 \mathrm{GHz}$ ) with a resonnat frequency at $3.93 \mathrm{GHz}$ with $26.67 \mathrm{~dB}$ reflection coefficient, as shown in Fig. 11 (b). The final cavity-backed antenna has a high directivity toward Zaxis as depicted in Fig. 12, achieving a directivity and realized gain of $7.95 \mathrm{dBi}$ and $7.37 \mathrm{~dB}$ at $4 \mathrm{GHz}$ (center frequency of Low-UWB band), respectively, as summarized in Table III.

This optimized final cavity-backed antenna is fed by coaxial cable instead of waveguide port, in the purpose of simulating a realistic measurement scenario. From Fig. 11 (b) one can notice the absence of the undesired resonant frequency by this feeding method. Beside the required bandwidth of (3.51-4.35 GHz) is still achieved with a resonance frequency with $-26.67 \mathrm{~dB}$ at $3.93 \mathrm{GHz}$. Regarding the antenna matching, according to results shown in Fig. 13 (a) the antenna input impedance is about $52+\mathrm{j} 6.6 \Omega$. The cavity-backed antenna radiates well over the bandwidth of our interest in terms of simulated total efficiency as shown in Fig. 13 (b).

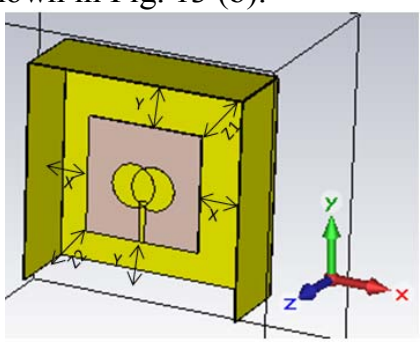

Fig. 10. Low-UWB cavity-backed antenna.

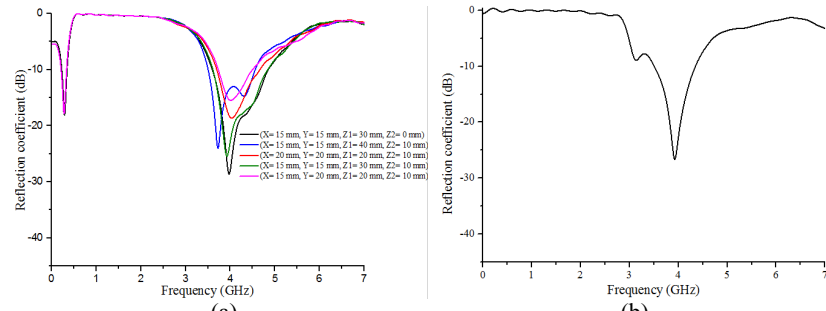

Fig. 11. (a) Reflection coefficient of the cavity-backed Low-UWB antenna by tuning the cavity dimensions.(b) Reflection coefficient of the final optimized Low-UWB cavity-backed antenna.
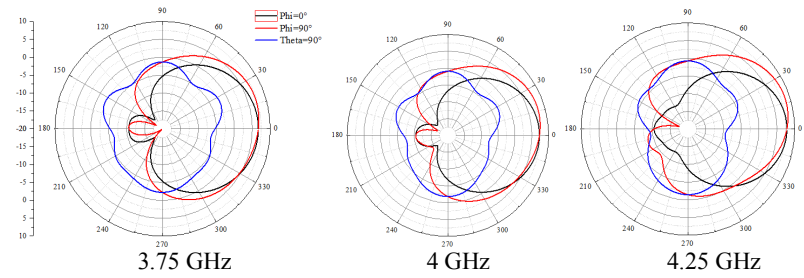

Fig. 12. Radiation pattern in $\mathrm{dBi}$ of the Low-UWB cavity-backed antenna.

TABLE III: REALIZED GAIN VALUES OF THE LOW-UWB SINGLE ANTENNA

\begin{tabular}{|c|c|c|c|}
\hline $\begin{array}{c}\text { Frequency } \\
(\mathrm{GHz})\end{array}$ & $\begin{array}{c}\mathrm{Phi}=0^{\circ} \\
(\mathrm{dB})\end{array}$ & $\begin{array}{c}\text { Phi }=90^{\circ} \\
(\mathrm{dB})\end{array}$ & $\begin{array}{c}\text { Theta }=90^{\circ} \\
(\mathrm{dB})\end{array}$ \\
\hline 3.75 & 2.60 & 2.61 & -0.65 \\
\hline 4 & 2.58 & 2.60 & -0.76 \\
\hline 4.25 & 2.03 & 2.05 & -0.80 \\
\hline
\end{tabular}



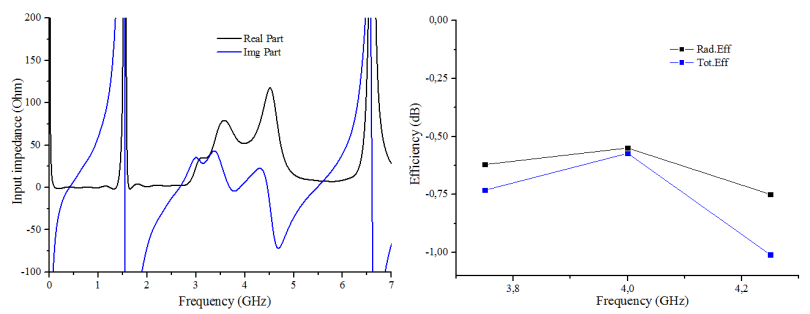

Fig. 13. (a) Input impedance and (b) Radiation and Total efficiency of the Low-UWB cavity-backed antenna.

\section{ON-BODY STUDY}

This section presents a brief and preliminary on-body study using the combination of two proposed antennas (introduced in Section II) which are the single and cavitybacked Low-UWB antenna. The antenna behavior of both structures is investigated in vicinity of human body (smallintestine area of the GI tract) and compared to free-space results serving of reference. This body part is modelled by a multi-layer model with 6 tissue layers with proper dielectric properties. This is emulating different tissues organized in the following order: skin, fat, muscle, fat, SI (SmallIntestine) wall and SI content. Table IV lists the dielectric properties [10-13] and thicknesses of the different tissues. The values chosen for tissue thicknesses are meant to fulfill the criteria of a thin person (close to voxel model size). The multi-layer model used has a size an overall size of $240 \mathrm{~mm} \times 110 \mathrm{~mm} \times 74.4 \mathrm{~mm}$. A prior RF (Radio Frequency) propagation inside this multi-layer model is also discussed using both antenna configurations.

The calculation SAR (Specific Absorption Rate) values for single and cavity-backed structures are depicted in Fig. 14 (a) and (b) over a $0.001 \mathrm{~W}$ scale. The input power defined in CST software for this calculations were $0.001 \mathrm{~W}$. The calculated total SAR is $0.67 \mathrm{~mW} / \mathrm{kg}$ and $0.71 \mathrm{~mW} / \mathrm{kg}$ for $1 \mathrm{~g}$ mass average using single and cavity-backed structures, respectively. Those results proves that the antenna meets the safety guidance defined by the IEEE/IEC 42704-1 standard used.

Fig. 14 illustrates the two antenna layout in close proximity to the multi-layer model for single (c) and cavitybacked (d) antenna structures. In (d) the antennas are positionned side by side, while in (c) the same antenna disposition of the single antenna is maintained to have a

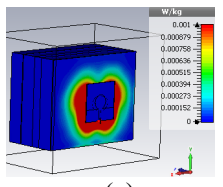

(a)

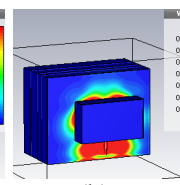

(b)

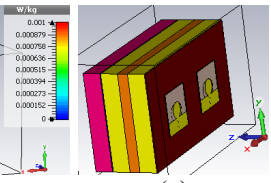

(c)

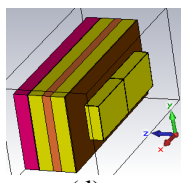

(d)
Fig. 14. SAR results for (a) Single and (b) cavity-backed Low-UWB antenna. (c) Two single and cavity-backed antennas in close proximity to human body.

TABLE IV: DIELECTRIC PROPERTIES AND THICKNESSES OF HUMAN TISSUES AT $4 \mathrm{GHz}$

\begin{tabular}{|l|l|l|l|}
\hline Tissue & Permittivity & $\begin{array}{l}\text { Conductivity } \\
(\mathrm{S} / \mathrm{m})\end{array}$ & $\begin{array}{l}\text { Thickness } \\
(\mathrm{mm})\end{array}$ \\
\hline Skin & 40.85 & 2.701 & 1.4 \\
\hline Fat1 & 5.125 & 0.1829 & 20 \\
\hline Muscle & 50.82 & 3.015 & 12 \\
\hline Fat2 & 5.125 & 0.1829 & 20 \\
\hline SI wall & 50.82 & 3.015 & 1 \\
\hline SI content & 51.63 & 4.622 & 20 \\
\hline
\end{tabular}

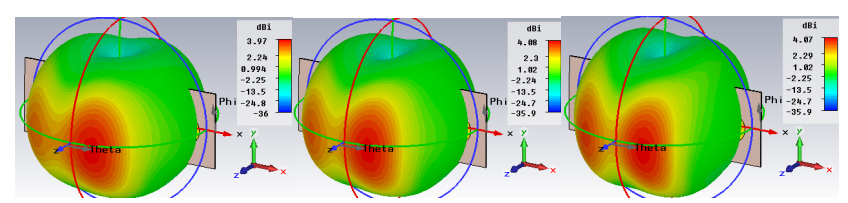

(a)

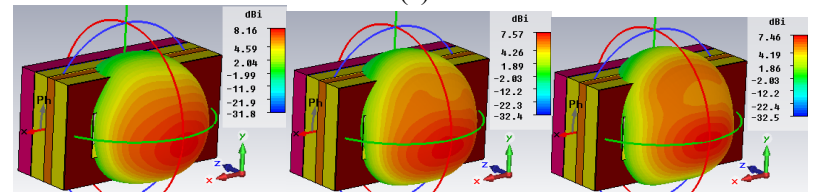

(b)

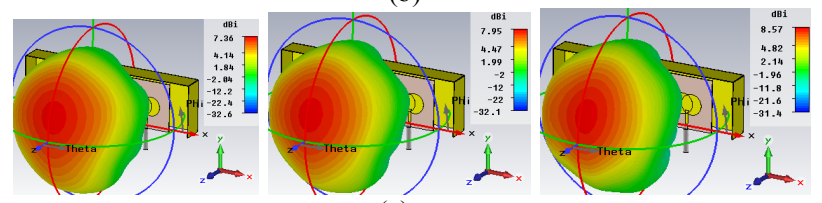

(c)

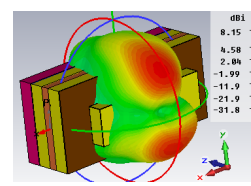

$3.75 \mathrm{GHz}$

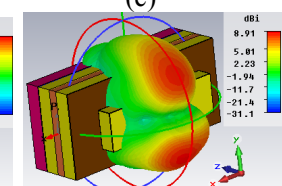

(d)
Fig. 15. 3D Directivity for (a) single antennas in free-space (Solo-FS) (b) single antennas on the body (Solo-OB) (c) cavity antennas in free-space (Cavity-FS) and (d) Cavity antennas on the body (Cavity-OB).

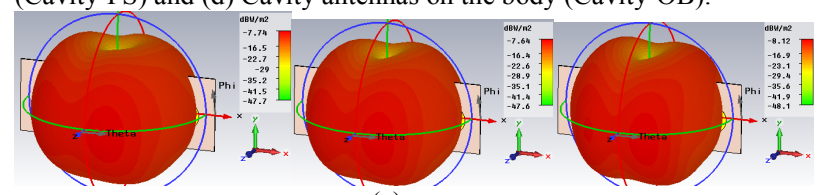

(a)

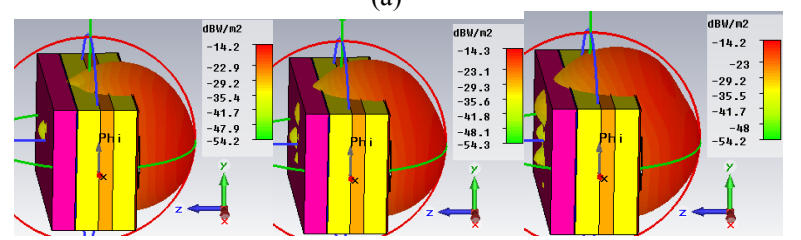

(b)
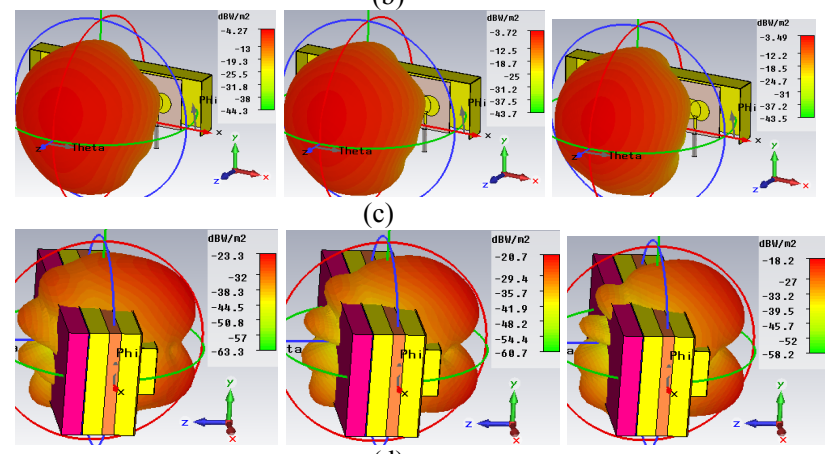

$3.75 \mathrm{GHz}$

$4 \mathrm{GHz}$

$4.25 \mathrm{GHz}$

Fig. 16. 3D Power pattern flow for (a) single antennas in free-space (SoloFS) (b) single antennas on the body (Solo-OB) (c) cavity antennas in freespace (Cavity-FS) and (d) Cavity antennas on the body (Cavity-OB).

comparable study case. Hence, the single antennas are separated by $36 \mathrm{~mm}$ distance. For the on-body scenario, the antennas are $4 \mathrm{~mm}$ away from the human body corresponding to a measurement case where a volunteer is wearing clothes.

Fig. 15 and 16 point out a precise investigation of the antenna performance in exposure to near human body by analyzing the directivity and power flow patterns, respectively. The directivity $3 \mathrm{D}$ results show that the backed 
directivity values in close proximity to human body are higher than the free-space ones for both single and cavitybacked antenna structures. At the center frequency $4 \mathrm{GHz}$, for exemple, the directivities using single and cavity-backed antennas on the body are 4.08 and $7.57 \mathrm{dBi}$, respectively. Similarly, these values are 7.95 and $8.91 \mathrm{dBi}$ for cavitybacked antenna structure. On the other hand, giving the focus on the cavity issue, it is easy to distinguish the improved directivity in the case of the cavity presence compared to the single antenna structure. This can be exemplified by the highest directivity returned from the multi-layer model for the cavity structure achieving $8.91 \mathrm{dBi}$ against $7.57 \mathrm{dBi}$ for single stucture at $4 \mathrm{GHz}$. Only this investigation outputs incite the cavity benefits for WCE localization (where reflected signals from the body are of primar interest).

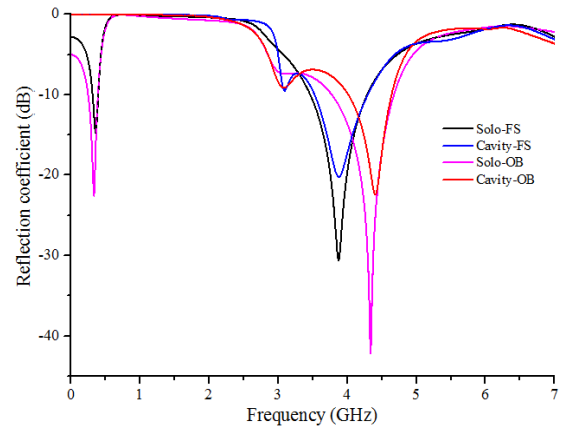

Fig. 17. Reflection coefficient comparison between single and cavitybacked approach in free-space and on-body scenarios.

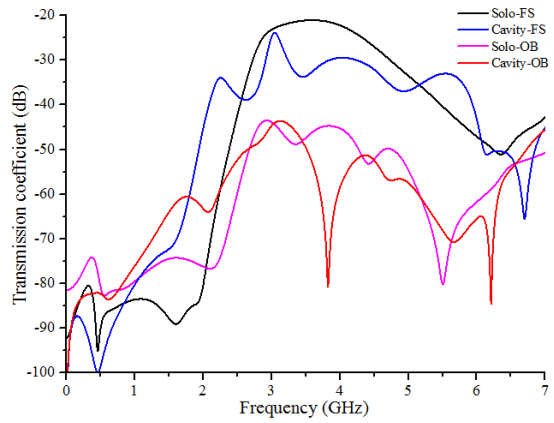

Fig.18. Transmission coefficient comparison between single and cavitybacked approach in free-space and on-body scenarios.

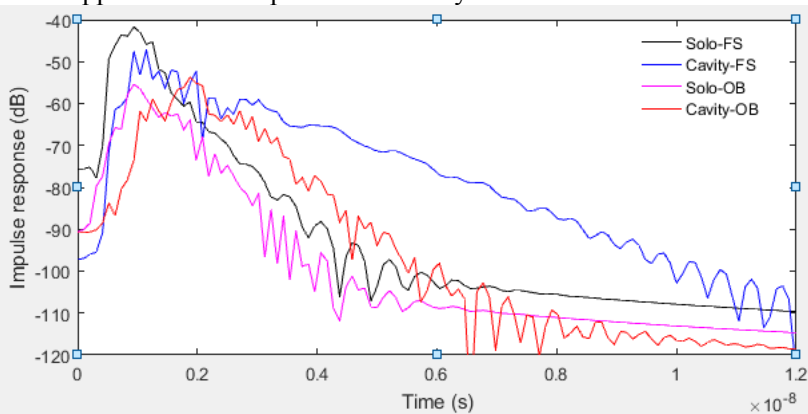

Fig.19. Impulse response comparison between single and cavity-backed approach in free-space and on-body scenarios.

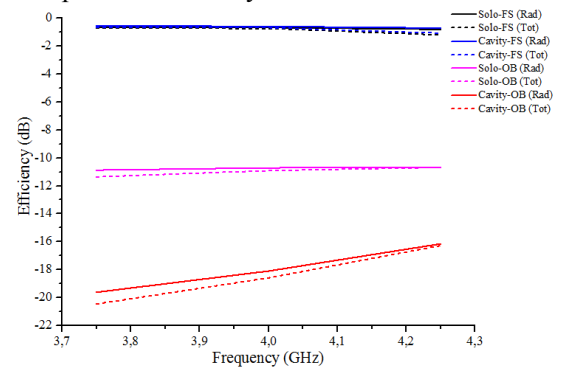

Fig.20. Radiation and total efficiency comparison between single and cavity-backed approach in free-space and on-body scenarios.

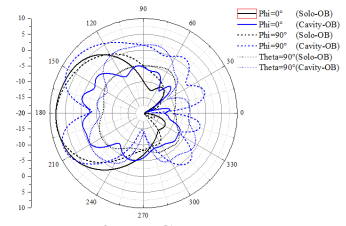

$3.75^{20} \mathrm{GHz}$

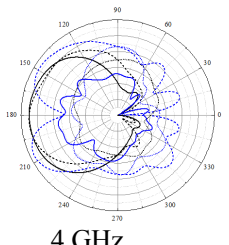

$4 \mathrm{GHz}$

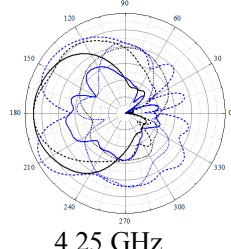

$4.25 \mathrm{GHz}$
Fig. 21. Radiation pattern comparison in $\mathrm{dBi}$ between single and cavitybacked approach in on-body scenario.

TABLE V: DIRECTIVITY CONPARISON VALUES OF THE SINGLE AND CAVITY-BACKED LOW-UWB ANTENNA

\begin{tabular}{|c|c|c|c|c|}
\cline { 2 - 5 } \multicolumn{1}{c|}{} & $\begin{array}{c}\text { Frequency } \\
(\mathrm{GHz})\end{array}$ & $\begin{array}{c}\mathrm{Phi}=0^{\circ} \\
(\mathrm{dBi})\end{array}$ & $\begin{array}{c}\text { Phi }=90^{\circ} \\
(\mathrm{dBi})\end{array}$ & $\begin{array}{c}\text { Theta }= \\
90^{\circ}(\mathrm{dBi})\end{array}$ \\
\hline \multirow{3}{*}{$\begin{array}{c}\text { Solo- } \\
\text { OB }\end{array}$} & 3.75 & 8.06 & 8.15 & -4.11 \\
\cline { 2 - 5 } & 4 & 7.48 & 7.55 & -2.23 \\
\cline { 2 - 5 } & 4.25 & 7.46 & 7.46 & -0.33 \\
\hline \multirow{3}{*}{$\begin{array}{c}\text { Cavity- } \\
\text { OB }\end{array}$} & 3.75 & 0.27 & 8.08 & 1.87 \\
\cline { 2 - 5 } & 4 & -1.31 & 8.79 & 1.56 \\
\cline { 2 - 5 } & 4.25 & -2.06 & 8.77 & 2.19 \\
\hline
\end{tabular}

These investigations are completed by power flow studies inside the human body (heterogenous model) as shown in Fig. 16. 3D patterns provide a clear visibility regarding the radiation penetration depth inside/within tissues. Comparing Fig. 16 (b) and (d), it is remarkable that the power flow decreases with tissue depth using the single structure. Not only this, but also the power intensity is not reaching entirelly the SI content layer. This is one limitation for the capsule endoscopy localization. However, this drawback is remediated by using cavity-backed approach which is clearly seen in Fig. 16 (d) since the power flows exceed largely and sufficiently the SI content layer. Hence, it is concluded that the cavity-backed approach is privileged for WCE localization ends. Add remark regarding unreached directivity in Fat 2 and SI using single antenna.

The antenna matching in vicinity to human body is compared for the case of single and cavity-backed approaches in Fig. 17. Results reveal a significant shift of the bandwidth and hence the resonance frequency. For single antenna, the reported bandwidths are $(3.47-4.28 \mathrm{GHz})$ and $(3.78-4.66 \mathrm{GHz})$ in free-space and on-body scenarios, respectively. For cavity-backed structure, these similar values are (3.51-4.35 GHz) and $(4.00-4.63 \mathrm{GHz})$. Besides, the maximum return loss and the resonant frequencies are higher in on-body scenarios compared to free-space. Whilst focusing on on-body study, it is inevitable that the cavity element affect meaningfuly the return loss value, and slightly the resonant frequency. However, the cavity alterates slightly the lower resonance from 3.78 to $4.00 \mathrm{~dB}$ by maintaining the upper frequency fixed to $4.64 \mathrm{GHz}$.

The channel characteristics are examined by a prime study case investigations where antenna cavities are side by side and compared with single antennas case and the findings are grouped in Fig. 18. Overally, on-body scenario provides high losses compared to free-space propagation, which is obvious because of the presence of lossy tissues.

For single antenna, the reported path loss in vicinity to human body is $45.28 \mathrm{~dB}$ compared to $22.24 \mathrm{~dB}$ in free-space. These similar corresponding values are -58.39 and $-29.46 \mathrm{~dB}$ for cavity backed structure. However, paying particular attention to on-body scenario, one can easily realize the 
reported high path loss when using cavity-backed structure in comparison to single antenna configuration (58.4 against $29.5 \mathrm{~dB}$ ). This emphasizes the evident explanation provided at the beginning of this section, which consist/traced backed to the additional reached human tissues by the propagated waves as shown previously in power flow figures.

Fig. 19 shows the impulse response comparison between single and cavity-backed approach in free-space and on-body scenarios by informing how the signal is propagated inside the multi-layer model. In free-space, both antenna structures have the same peak at $0.94 \mathrm{~ns}$ with $5.8 \mathrm{~dB}$ difference of power level. However, for on-body scenario, the peak signal is delayed by $0.938 \mathrm{~ns}$ using the cavity structure in comparison with the reference study case (free-space environment). This delay can be reasonably justified by the numerous reached lossy tissues causing a late arrival of the received signal by the receiving antenna. Still, this challenging issue needs to be investigated with an exhaustive study appealing E-field probes inside and at the surface of the different tissues.

The antenna efficiency decreases significantly in close proximity to human body as shown in Fig.20. This decrease is worst using cavity approach which can be explained by the additional radiations from the cavity component. The antenna directivity is plotted per cuts $\left(\mathrm{Phi}=0^{\circ}, \mathrm{Phi}=90^{\circ}\right.$ and Theta $=90^{\circ}$ ) as illustrated in Fig. 21. Table V summarizes the reported directivity values comparison between single and cavity structure of the proposed Low-UWB antennas for onbody scenario. At $4 \mathrm{GHz}$, maximum directivities are notified according to $\mathrm{Phi}=90^{\circ}$ for single and cavityèbacked antennas of $7.55 \mathrm{dBi}$ and $8.79 \mathrm{dBi}$.

\section{CONCLUSION AND PERSPECTIVES}

The paper introduces a new receiving antenna suitable for WCE localization purposes. Two antenna structures are presented and called single and cavity-backed configurations, both operating at Low-UWB range defined by bandwidth of $(3.75-4.25 \mathrm{GHz})$ with a $4 \mathrm{GHz}$ center frequency in compliance with IEEE 802.15.6 standard. The single and cavity-backed antennas have omni-directional and directional radiation patterns and achieving corresponding gains of 2.6 and $7.37 \mathrm{~dB}$, respectively. The proposed antennas are aimed to be held by a patient, which incites the preliminary on-body investigations with antenna-skin separation averaging clothes thickness (about $4 \mathrm{~mm}$ ) by using a multi-layer model. Radiations exhibited by the cavity approach attend/reach the deeper tissues, in this case Fat2, Small-intestine wall and content layers which are unreachable using simple approach. Both antenna configurations comply with SAR safety guidance defined by IEEE/IEC 42704-1 standard. A detailed on-body study using single and cavity-backed antennas will be done and validated with measurement in free-space and on-body volunteers.

\section{ACKNOWLEDGMENT}

Authors would like to thank Professor Jantunen Heli and all in Microelectronics research unit team for the help on antenna design.

This work was financially supported by ERASMUS+ program, Key 1 - Mobility for learners and staff - for the cooperation between Microelectronics Research Unit and Centre for Wireless Communications, University of Oulu, Finland, and Ibn Tofail University, Electronics and Telecommunication systems research unit, Morocco. The work was partly supported by the Academy of Finland project 6Genesis Flagship (grant no. 318927).

\section{REFERENCES}

[1] A. Sabban, "New Wideband Printed Antennas for Medical Applications", IEEE Transactions on Antennas and Propagation, vol. 61, I. 1, pp. $84-91,2013$.

[2] G-. P. Gao ; B. Hu ; S-. F. Wang and C. Yang, "Wearable Circular Ring Slot Antenna With EBG Structure for Wireless Body Area Network", IEEE Antennas and Wireless Propagation Letters, Vol. 17, pp. $434-437,2018$.

[3] IEEE Standard for Local and metropolitan area networks Part 15.6: Wireless Body Area Networks, pp. IEEE Std 802.15.6-2012, pp. 1 271, 2012.

[4] K. M. Thotahewa, J-M. Redoute and M. R. Yuce, "Electromagnetic power absorption of the human abdomen from IR-UWB based wireless capsule endoscopy devices, IEEE International Conference on Ultra-Wide Band (ICUWB), Sydney, Australia, Sept. 2013.

[5] D. Anzai; K. Katsu; R. C-. Santiago; Q. Wang; Dirk Plettemeier; J. Wang; I.Balasingham, "Experimental Evaluation of Implant UWB-IR Transmission With Living Animal for Body Area Networks", IEEE Transactions on Microwave Theory and Techniques, vol. 62, pp. $183-192,2014$.

[6] D. Goswami; K. C. Sarma; A. Mahanta, "Path loss variation of onbody UWB channel in the frequency bands of IEEE 802.15.6 standard", Healthcare Technology Letters, vol. 3, pp. 129-135, 2016.

[7] D. Micic; C. E. Semrad, "Small Bowel Endoscopy", Current Treatment Options in Gastroenterology, Volume 14, Issue 2, pp 220235, 2016.

[8] B. H. K. Leung; C. C. Y. Poon; R. Zhang; Y. Zheng; C. K. W. Chan; P. W. Y. Chiu; J. Y. W. Lau; J. J. Y. Sung, "A Therapeutic Wireless Capsule for Treatment of Gastrointestinal Haemorrhage by Balloon Tamponade Effect", IEEE Transactions on Biomedical Engineering, vol. 64, pp. 1106-1114, 2017.

[9] T. Dissanayake, M. R. Yuce, and C. Ho, "Design and evaluation of a compact antenna for implant-to-air UWB communication," IEEE Antennas Wireless Propagat. Lett., vol. 8, pp. 153-156, 2009.

[10] S.M. Bunce, A.P. Moore, A.D. Hough, "M-mode ultrasound: a reliable measure of trans-versus abdominis thickness?", Clinical Biomechanics, vol. 17, pp. 315-317, 2002.

[11] O. Akkus, A. Oguz, M. Uzunlulu* and M. Kizilgul, "Evaluation of Skin and Subcutaneous Adipose Tissue Thickness for Optimal Insulin Injection", Diabetes \& Metabolism, pp. 3-8, 2012.

[12] http://www.fcc.gov/oet/rfsafety/dielectric.html

[13] https://www.itis.ethz.ch/virtual-population/tissueproperties/database/dielectric-properties/ 